\title{
Genetic Variants of the MDM2 Gene Are Predictive of Treatment-Related Toxicities and Overall Survival in Patients With Advanced NSCLC
}

\author{
Ji Qian, ${ }^{1,2}$ Hongliang Liu, ${ }^{3}$ Shaohua Gu, ${ }^{2}$ Qihan Wu, ${ }^{4}$ Xueying Zhao, ${ }^{2}$ \\ Wenting Wu, ${ }^{2,5}$ Haijian Wang, ${ }^{2}$ Jiucun Wang, ${ }^{2}$ Hongyan Chen, ${ }^{2}$ Wei Zhang, \\ Qingyi Wei, ${ }^{1,3} \mathrm{Li}$ Jin, ${ }^{2}$ Daru Lu ${ }^{2}$
}

\section{Abstract}

We investigated the association of 5 tagging single nucleotide polymorphisms (SNPs) of MDM2 with chemotherapy-related toxicities and clinical outcomes in 663 patients with advanced non-small-cell lung cancer. We identified 2 SNPs (rs1470383 and rs1690924) with significant associations with chemotherapyrelated toxicities. One SNP rs1470383 also influenced the overall survival of patients without overall toxicity or hematologic toxicity.

Introduction: Platinum agents can cause the formation of DNA adducts and induce apoptosis to eliminate tumor cells. The aim of the present study was to investigate the influence of genetic variants of MDM2 on chemotherapy-related toxicities and clinical outcomes in patients with advanced non-small-cell lung cancer (NSCLC). Materials and Methods: We recruited 663 patients with advanced NSCLC who had been treated with first-line platinum-based chemotherapy. Five tagging single nucleotide polymorphisms (SNPs) in MDM2 were genotyped in these patients. The associations of these SNPs with clinical toxicities and outcomes were evaluated using logistic regression and Cox regression analyses. Results: Two SNPs (rs1470383 and rs1690924) showed significant associations with chemotherapy-related toxicities (ie, overall, hematologic, and gastrointestinal toxicity). Compared with the wild genotype AA carriers, patients with the GG genotype of rs 1470383 had an increased risk of overall toxicity (odds ratio [OR], 3.28; 95\% confidence interval [Cl], 1.34-8.02; $P=.009$ ) and hematologic toxicity (OR, 4.10; 95\% Cl, 1.73-9.71; $P=.001$ ). Likewise, patients with the AG genotype of rs 1690924 showed more sensitivity to gastrointestinal toxicity than did those with the wild-type homozygote $\mathrm{GG}(\mathrm{OR}, 2.32 ; 95 \% \mathrm{Cl}, 1.30-4.14 ; P=.004)$. Stratified survival analysis revealed significant associations between rs1470383 genotypes and overall survival in patients without overall or hematologic toxicity $(P=.007$ and $P=.0009$, respectively). Conclusion: The results of our study suggest that SNPs in MDM2 might be used to predict the toxicities of platinum-based chemotherapy and overall survival in patients with advanced NSCLC. Additional validations of the association are warranted.

Clinical Lung Cancer, Vol. 16, No. 5, e37-53 @ 2015 Elsevier Inc. All rights reserved.

Keywords: Non-small-cell lung cancer, Platinum-based chemotherapy, Polymorphisms, Progression-free survival, Toxicity

J.Q. and H.L. contributed equally to this work.

${ }^{1}$ Cancer Institute, Fudan University Shanghai Cancer Center, and Department of Oncology, Fudan University Shanghai Medical College, Shanghai, China

${ }^{2}$ State Key Laboratory of Genetic Engineering and MOE Key Laboratory of

Contemporary Anthropology, Fudan University School of Life Sciences and Fudan Taizhou Institute of Health Sciences, Shanghai, China

${ }^{3}$ Duke Cancer Institute, Duke University Medical Center, Durham, NC

${ }^{4}$ East China Normal University School of Life Science, Shanghai, China

${ }^{5}$ Beyster Center for Genomics of Psychiatric Diseases, Department of Psychiatry,

University of California, San Diego, La Jolla, CA

${ }^{6}$ Department of Respiratory Disease, Shanghai Chest Hospital, Shanghai Jiaotong

University, Shanghai, China
Submitted: Dec 15, 2014; Revised: Feb 9, 2015; Accepted: Feb 10, 2015; Epub: Feb 19, 2015

Address for correspondence: Ji Qian, PhD, State Key Laboratory of Genetic Engineering and MOE Key Laboratory of Contemporary Anthropology, School of Life Sciences, Fudan University, Handan Road, Shanghai 200433, China and Daru Lu, State Key Laboratory of Genetic Engineering and MOE Key Laboratory of Contemporary Anthropology, School of Life Science, Fudan University, Handan Rd., Shanghai 200433, China.

E-mail contact: jiqian@fudan.edu.cn, darulu@hotmail.com 


\section{MDM2 SNPs Predict Toxicities and Survival in Advanced NSCLC}

\section{Introduction}

Lung cancer is the leading cause of cancer death in the world, and non-small-cell lung cancer (NSCLC) accounts for nearly $80 \%$ to $85 \%$ of all lung cancer cases. ${ }^{1}$ Platinum-based doublet regimens are widely used as the first-line treatment of patients with advanced NSCLC and lead to improved survival outcomes. ${ }^{2}$ However, a number of patients who received platinum-based treatment developed high grade toxicities, which might decrease treatment efficiency or cause therapy withholding. ${ }^{3}$ Identification of the inherited variants associated with platinum-based therapy toxicities and outcomes would be useful in making suitable individualized treatment plans.

Platinum drugs might inhibit tumor growth mainly by the formation of platinum-DNA adducts and intrastrand/interstrand crosslinks, which result in cell cycle arrest and apoptosis. ${ }^{3}$ The p53 gene plays a central role in cell cycle control, DNA repair, and apoptosis initiation. ${ }^{4}$ In many cellular processes, MDM2 acts as a key negative regulator of p53 through directing binding, ubiquitination, and degradation of $\mathrm{p} 53 .^{5}$ Many cancer cells display high levels of MDM2 expression, resulting in rapid cancer progression and a lack of response to therapy in a subset of human cancers. ${ }^{6,7}$ However, in NSCLC, overexpression of MDM2 was associated with favorable survival outcomes. ${ }^{8-10}$ Such disparity might be resulted from the relative importance of p53-dependent and p53-independent functions of MDM2 in different cancers. ${ }^{7}$ In NSCLC, MDM2 might play a role in p53-independent antitumor activity (eg, as a regulator of cell proliferation).

Single nucleotide polymorphisms (SNPs) have been shown to influence gene functions and clinical phenotypes. ${ }^{11}$ Currently, 2 functional SNPs, SNP309 (rs2279744) ${ }^{12}$ and its antagonist SNP285 (rs117039649), ${ }^{13}$ have been reported to enhance and decrease MDM2 gene expression, respectively. SNP309 has divergent minor allele frequency among different populations. Also, SNP285 is only observed in whites but not in Asians. The associations between these functional SNPs and cancer risk have been evaluated in different types of cancers. ${ }^{14-16}$ However, until now, few studies have investigated the effect of MDM2 SNPs on chemotherapy toxicity. ${ }^{17,18}$ In the present study, we selected 5 tagging SNPs in MDM2 to evaluate their associations with chemotherapy toxicity and clinical outcomes in 663 patients with advanced NSCLC who had received first-line platinum-based chemotherapy.

\section{Materials and Methods Study Population}

In the present study, we recruited patients with histologically confirmed advanced NSCLC from 3 hospitals in Shanghai, China, from March 2005 to January 2010 (Shanghai Chest Hospital, Shanghai Zhongshan Hospital, and Shanghai Changhai Hospital). The criteria for patient recruitment have been detailed previously. ${ }^{19}$ In brief, our study enrolled 663 eligible patients who had been diagnosed with stage IIIA-IV NSCLC and had been given first-line platinum-based chemotherapy without any previous surgery, radiotherapy, or concurrent chemoradiotherapy. All chemotherapeutic drugs were administered intravenously, and all patients were treated for 2 to 6 cycles. The chemotherapy toxicities were assessed twice a week. The grade of toxicity was recorded using the National Cancer Institute Common Toxicity Criteria, version 3.0, including overall toxicity, gastrointestinal toxicity (nausea/vomiting), and hematologic toxicity (including leukocytopenia, agranulocytosis, anemia, and thrombocytopenia). The toxicity outcome was dichotomized by the presence or absence of any grade 3 or 4 overall toxicity, any grade 3 or 4 gastrointestinal toxicity, and any grade 3 or 4 hematologic toxicity.

The demographic and other clinical data (ie, sex, age, smoking history, family history of cancer, clinical stage, and tumor histologic type) were collected at entry to the study. Survival were collected from several sources, including follow-up telephone interviews, the Social Security Death Index, and inpatient and outpatient clinical medical records. The ethical review committee of Fudan University and the hospitals approved the study protocol. All participants provided written informed consents.

\section{SNP Selection and Genotyping}

TagSNPs were selected according to the HapMap phase II data with 44 unrelated individuals from Tokyo, Japan (JPT) and 45 unrelated Han Chinese individuals from Beijing, China (CHB). There are 16 SNPs within $2 \mathrm{~kb}$ up- and downstream of the MDM2 gene with a minor allele frequency $(\mathrm{MAF})>0.05$. As shown in Supplemental Figure 1 (available in the online version), 6 tagging SNPs were selected using SNPinfo (available at: http://snpinfo. niehs.nih.gov/snpinfo/snptag.htm) with a minimum pairwise linkage disequilibrium (LD) r2 threshold of 0.8. However, 5 of them could pass the genotyping quality control.

Blood samples were obtained at entry to the study and stored in ethylenediaminetetraacetic acid tubes at $-80^{\circ} \mathrm{C}$. The QIAamp DNA Maxi Kit (Qiagen $\mathrm{GmbH}$ ) was used to extract genomic DNA. We used iSelect HD BeadChip (Illumina) to genotype the selected SNPs in MDM2 with the following quality control criteria: genotyping call rate of SNP $\geq 0.95, \mathrm{MAF} \geq 0.01$, and GenCall score $\geq 0.2$. GenomeStudio, version 2010.1, and GeneMap software were used to analyze the data and prepare the reports. Concordance between replicates was $>99.9 \%$.

\section{Statistical Analysis}

The Hardy-Weinberg equilibrium was tested using Pearson's $\chi^{2}$ test. The associations between genotypes and toxicity outcomes were assessed using the $\chi^{2}$ test and logistic regression analyses with or without adjustment for other significant demographic and clinical variables. Sex and chemotherapy regimens were significant related factors for gastrointestinal toxicity and hematologic toxicity, respectively. For overall toxicity, both patient sex and chemotherapy regimen were significantly influential factors and were included as adjusted covariates. Progression-free survival (PFS) was calculated from the date of the patient started chemotherapy to the date of disease progression or death (whichever occurred first) or the last follow-up visit. Overall survival (OS) was calculated from the date of the first chemotherapy session to the date of death from any cause or the last follow-up visit. The median PFS and OS were estimated using the Kaplan-Meier method, and their differences by genotypes were tested using the log-rank test. Univariate and multivariate Cox regression analyses were used to estimate the hazard ratio (HR) and $95 \%$ confidence 
Table 1 Distribution of Clinical Characteristics Stratified by Chemotherapy Toxicity

\begin{tabular}{|c|c|c|c|c|c|c|c|c|c|}
\hline \multirow[b]{2}{*}{ Characteristic } & \multicolumn{3}{|c|}{ GI Toxicity ${ }^{\mathrm{a}}$} & \multicolumn{3}{|c|}{ Hematologic Toxicity ${ }^{b}$} & \multicolumn{3}{|c|}{ Overall Toxicity } \\
\hline & No & Yes & $P$ Value & No & Yes & $P$ Value & No & Yes & $P$ Value \\
\hline Total patients & $587(91.0)$ & $58(9.0)$ & & $482(74.4)$ & $166(25.6)$ & & $437(68.6)$ & $200(31.4)$ & \\
\hline Age (years) & & & .805 & & & .344 & & & .306 \\
\hline Median & 58 & 59.5 & & 58 & 60 & & 58 & 60 & \\
\hline Range & $26-80$ & $34-78$ & & $26-80$ & $28-78$ & & $26-80$ & $28-78$ & \\
\hline Sex & & & $<.0001^{\circ}$ & & & 216 & & & $.015^{\circ}$ \\
\hline Male & $424(72.2)$ & $25(43.1)$ & & $344(71.4)$ & $110(66.3)$ & & $317(72.5)$ & $126(63.0)$ & \\
\hline Female & $163(27.8)$ & $33(56.9)$ & & $138(28.6)$ & $56(33.7)$ & & $120(27.5)$ & $74(37.0)$ & \\
\hline ECOG PS & & & .476 & & & .478 & & & .646 \\
\hline $0-1$ & $540(92.3)$ & $52(89.7)$ & & $439(91.7)$ & $155(93.4)$ & & $400(92.0)$ & $186(93.0)$ & \\
\hline 2 & $45(7.7)$ & $6(10.3)$ & & $40(8.3)$ & $11(6.6)$ & & $35(8.0)$ & $14(7.0)$ & \\
\hline Smoking status ${ }^{d}$ & & & $.001^{\circ}$ & & & 347 & & & 101 \\
\hline Never smokers & $234(39.9)$ & $36(62.1)$ & & $196(40.7)$ & $74(44.9)$ & & $174(39.8)$ & $93(47.0)$ & \\
\hline Ever smokers & $352(60.1)$ & $22(37.9)$ & & $286(59.3)$ & $91(55.1)$ & & $263(60.2)$ & $106(53.0)$ & \\
\hline TNM stage & & & .933 & & & .925 & & & .924 \\
\hline IIIA & $43(7.4)$ & $5(8.6)$ & & $35(7.3)$ & $13(7.8)$ & & $31(7.1)$ & $16(8.0)$ & \\
\hline$\| \mathrm{IIB}$ & $168(28.7)$ & $16(27.6)$ & & $140(29.2)$ & $46(27.7)$ & & $124(28.5)$ & $57(28.5)$ & \\
\hline IV & $374(63.9)$ & $37(63.8)$ & & $305(63.5)$ & 107 (64.5) & & $280(64.4)$ & $127(63.5)$ & \\
\hline Histologic type & & & .462 & & & .942 & & & .509 \\
\hline Adenocarcinoma & $385(65.8)$ & $36(62.1)$ & & $314(65.4)$ & $111(66.9)$ & & $287(66.0)$ & $131(65.5)$ & \\
\hline Squamous cell carcinoma & $123(21.0)$ & $11(19.0)$ & & $103(21.5)$ & $32(19.3)$ & & $96(22.0)$ & $38(19.0)$ & \\
\hline Adenosquamous carcinoma & $10(1.7)$ & $2(3.5)$ & & $9(1.9)$ & $3(1.8)$ & & $6(1.4)$ & $5(2.5)$ & \\
\hline Other ${ }^{e}$ & 67 (11.5) & $9(15.5)$ & & $54(11.3)$ & $20(12.1)$ & & $46(10.6)$ & $26(13.0)$ & \\
\hline Platinum chemotherapy regimen & & & .189 & & & $.012^{\circ}$ & & & $.006^{\circ}$ \\
\hline Navelbine & $182(31.0)$ & $22(37.9)$ & & $143(29.7)$ & $62(37.4)$ & & $125(28.6)$ & $73(36.5)$ & \\
\hline Gemcitabine & $133(22.7)$ & $16(27.6)$ & & $111(23.0)$ & $40(24.1)$ & & $99(22.7)$ & $49(24.5)$ & \\
\hline Paclitaxel & $191(32.5)$ & $10(17.3)$ & & $164(34.0)$ & $37(22.3)$ & & $156(35.7)$ & $44(22.0)$ & \\
\hline Docetaxel & $48(8.2)$ & $5(8.6)$ & & $33(6.9)$ & $20(12.0)$ & & $31(7.1)$ & $23(11.5)$ & \\
\hline Other combinations & $33(5.6)$ & $5(8.6)$ & & $31(6.4)$ & $7(4.2)$ & & $26(5.9)$ & $11(5.5)$ & \\
\hline
\end{tabular}

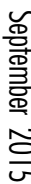




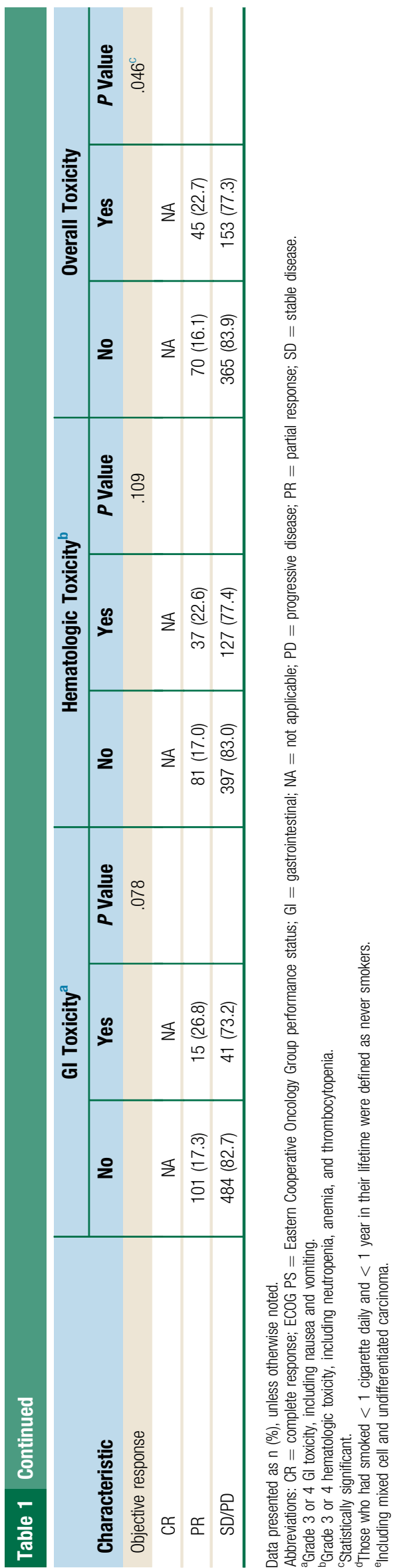

interval (CI) with and without adjustment for age and sex, together with the other clinical variables that had a significant association with OS or PFS (Supplemental Table 2; available in the online version).

Stratified analyses were performed by age, sex, smoking status, TNM stage, histologic type, and chemotherapy regimen. To evaluate the joint effects of SNPs in MDM2, we also performed haplotype analysis. Haploview software was used to define the blocks according to the algorithm of confidence bound on $\mathrm{D}$ prime of each pair of SNPs by standard Haploview parameters. ${ }^{20}$ The expectation-maximization algorithm implemented in SAS, the genetic module, was used to infer the haplotypes and their frequencies. The false-positive report probability (FPRP) was calculated to adjust for false-positive findings. ${ }^{21}$ For all significant results in the study, we calculated the FPRP values using 3 factors: prior probability of a true association of the tested genetic variant with a disease ( 2 prior probabilities were assumed to be 0.1 and 0.01 ), the observed $P$ value, and the statistical power to detect the odds ratio of the alternative hypothesis at the given $P$ value (the prior effect size was assumed to be 2.5 and 1.5 for SNPs for platinum toxicity and OS, respectively). An association was considered noteworthy when its FPRP value was $<0.2$.

All tests of statistical significance were two sided. If not specifically mentioned, all statistical analyses were performed using Statistical Analysis Systems software, version 9.2 (SAS Institute Inc., Cary, NC).

\section{Results}

All the patients in the present study had histologically confirmed stage IIIA-IV NSCLC. The main demographic and clinical characteristics have been previously described. ${ }^{19}$ Of 648 patients, 166 had grade 3 or 4 hematologic toxicity; 58 of 645 patients had grade 3 or 4 gastrointestinal toxicity, and 200 of 637 patients had overall toxicity (Table 1). Females and never smokers had a significantly greater risk of gastrointestinal toxicity compared with males and smokers $(P<.0001$ and $P=.001$, respectively). The chemotherapy regimens were significantly associated with hematologic toxicity $(P=.012)$ and overall toxicity $(P=.006)$. In addition, significant differences were seen in the sex distribution of patients with and without overall toxicity $(P=.015)$. The patients who experienced overall toxicity had a greater partial response rate $(22.0 \%)$ than did those without toxicity (partial response rate, $16.1 \% ; P=.045$ ). No significant associations were found between chemotherapy toxicities and OS or PFS (Supplemental Table 2; available in the online version). The frequency distributions of the 5 tagging SNPs are summarized in Supplemental Table 1 (available in the online version). All were in Hardy-Weinberg equilibrium $(P>.05)$. We also calculated the pairwise $\mathrm{LD}$ of these 5 SNPs in our sample. Low pairwise LD $(\mathrm{r} 2<0.5)$ was found among them (Figure 1).

\section{Association Between Single Locus and Chemotherapy Toxicity}

The significant associations between the SNPs and toxicity outcomes are listed in Table 2. One intron SNP rs1470383 showed significant influence on overall toxicity and hematologic toxicity with 


\section{Chr12q14.3-q15: MDM2/NM_002392.5}
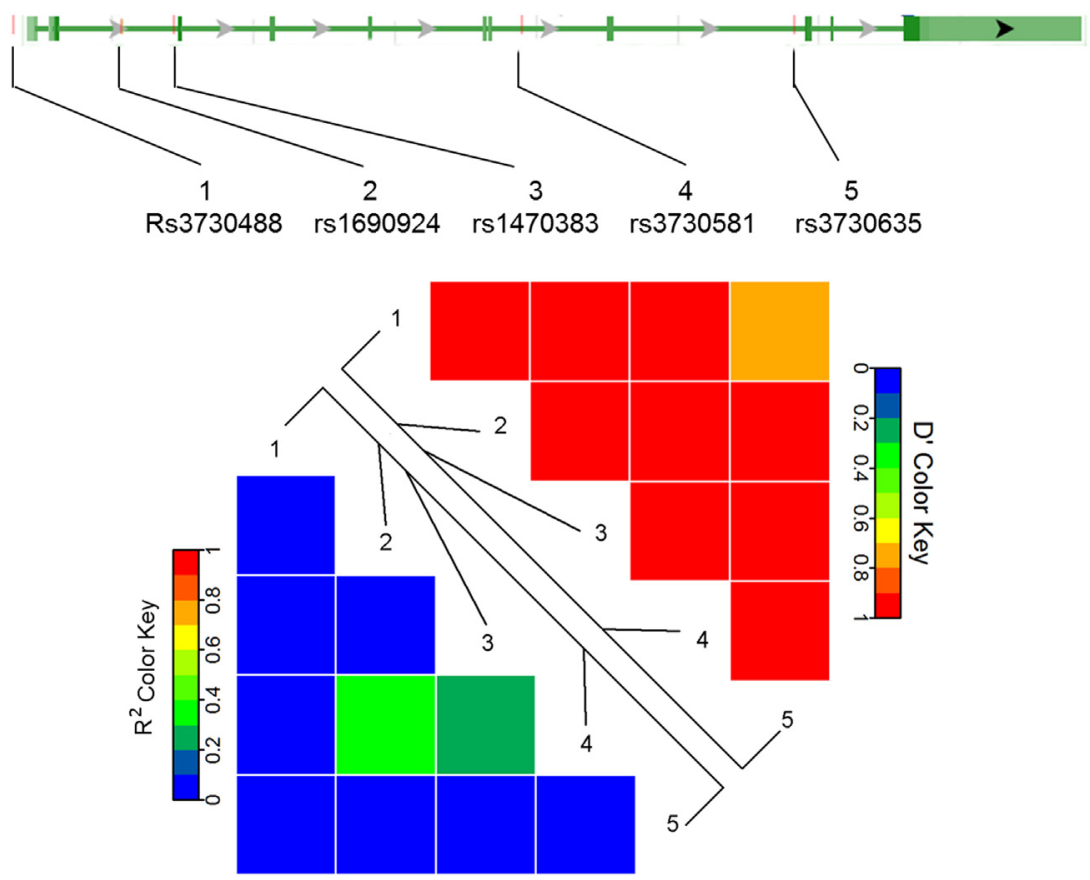

adjustment for sex and chemotherapy regimen. Compared with the wild-type AA homozygotes, patients with the GG genotype tended to have a higher risk of hematologic toxicity (OR, 4.10;95\% CI, 1.73-9.71; $P=.001$ ) and overall toxicity (OR, 3.28; $95 \%$ CI, 1.34-8.02; $P=.009)$. These associations were even more significant under a recessive model $(P=.007$ for overall toxicity and $P=.001$ for hematologic toxicity). For rs1690924, the AG heterozygotes had an increased risk of gastrointestinal toxicity (OR, 2.32; 95\% CI, 1.30-4.14; $P=.004)$ compared with the AA homozygotes.

We also assessed the discriminative accuracy of the prediction model with and without adding these identified SNPs to the significant demographic and clinical features (sex and chemotherapy regimen) by comparing the area under the receiver operating characteristic curve (AUC) (Supplemental Figure 2; available in the online version). When adding rs 1470383 in the prediction model of hematologic toxicity, the AUC increased to 0.61 (95\% CI, 0.56-0.66) compared with the model that only included the chemotherapy regimen (AUC, 0.59; 95\% CI, 0.54-0.64; $P=$ $.103)$. For overall toxicity, the AUC increased slightly to 0.61 (95\% CI, 0.57-0.66) when adding rs1470383 to the model compared with the AUC for the model that only included the 2 variables of sex and chemotherapy regimen (AUC, 0.60; 95\% CI, 0.56-0.65; $P=.283$ ). For gastrointestinal toxicity, the AUC increased to 0.71 (95\% CI, 0.64-0.78) after including rs1690924 in the model compared with the AUC for the model that only included sex and chemotherapy regimen (AUC, 0.65; 95\% CI, 0.58-0.71; $P=.002)$.

\section{Associations Between SNPs and OS and PFS}

One SNP (rs3730635) showed a marginally significant association with lung cancer OS (log-rank, $P=.036$; Table 3, Figure $2 \mathrm{~A}$ ). Patients with the heterozygous AG genotype had longer survival than those with the AA genotype (median OS time, 29.5 vs. 17.8 months; HR, 0.54; 95\% CI, 0.29-1.01). No significant association was found for the other SNPs.

Haplotype analysis was also performed for the 3 SNPs (rs1690924, rs1470383, and rs3730581) that were defined in the same block in Haploview. Haplotype "AAG" was significantly associated with favorable survival (HR, 0.66; 95\% CI, 0.46-0.95; $P=.025$; Table 3).

\section{Stratified Analysis}

We also evaluated the association between SNPs and OS stratified by toxicity (overall toxicity, gastrointestinal toxicity, and hematologic toxicity). In the subpopulation of patients who experienced overall toxicity, those that were heterozygous for rs3740588 experienced a shorter OS than those with the AA genotype (median OS time, 13.3 vs. 18.7 months; $P=.049$; Table 4, Figure 2B, C). For those who experienced severe hematologic toxicity, rs1690924 was shown to significantly influence survival $(P=.043)$. However, no significance remained after adjustment for age, sex, TNM stage, and histologic type.

Another 2 SNPs (rs1470383 and rs3730635) were significantly associated with OS in patients without toxicities (Table 4, Figure 2D, E). For SNP rs1470383, the survival of patients without 
Table 2 Association of MDM2 SNPS and Chemotherapy Toxicity

\begin{tabular}{|c|c|c|c|c|c|c|c|c|c|c|c|c|}
\hline \multirow[b]{2}{*}{ SNP } & \multicolumn{4}{|c|}{ Gastrointestinal Toxicity } & \multicolumn{4}{|c|}{ Hematologic Toxicity } & \multicolumn{4}{|c|}{ Overall Toxicity } \\
\hline & Total & $\begin{array}{l}\text { Toxicity } \\
\text { Present }\end{array}$ & OR $\left(95 \%\right.$ Cl) ${ }^{\mathrm{a}}$ & $P$ Value $^{\mathrm{a}}$ & Total & $\begin{array}{l}\text { Toxicity } \\
\text { Present }\end{array}$ & OR $(95 \% \mathrm{Cl})^{\mathrm{b}}$ & $P$ Value $^{b}$ & Total & $\begin{array}{l}\text { Toxicity } \\
\text { Present }\end{array}$ & OR $(95 \% \mathrm{Cl})^{\mathrm{C}}$ & $P$ Value \\
\hline \multicolumn{13}{|l|}{ rs3730488 } \\
\hline AA & 601 & $53(8.8)$ & 1.00 (Ref) & - & 602 & $151(25.1)$ & 1.00 (Ref) & - & 593 & $184(31.0)$ & 1.00 (Ref) & .370 \\
\hline$A C$ & 42 & $5(11.9)$ & $1.35(0.50-3.65)$ & .559 & 44 & $15(34.1)$ & $1.52(0.78-2.93)$ & .216 & 42 & $16(38.1)$ & $1.35(0.7-2.61)$ & .987 \\
\hline $\mathrm{CC}$ & 1 & NA & NA & NA & 1 & NA & NA & NA & 1 & NA & NA & NA \\
\hline Recessive & & & NA & .989 & & & NA & .982 & & & NA & NA \\
\hline \multicolumn{13}{|l|}{ rs1690924 } \\
\hline AA & 333 & $21(8.8)$ & 1.00 (Ref) & - & 334 & $87(26.0)$ & 1.00 (Ref) & - & 330 & $96(29.1)$ & 1.00 (Ref) & - \\
\hline$A G$ & 260 & $35(13.5)$ & $2.32(1.30-4.14)$ & $.004^{d}$ & 260 & 68 (26.2) & $1.04(0.72-1.52)$ & .826 & 254 & $91(35.8)$ & $1.42(1.00-2.04)$ & .053 \\
\hline GG & 52 & $2(3.9)$ & $0.58(0.13-2.57)$ & .471 & 54 & $11(20.4)$ & $0.76(0.37-1.55)$ & .450 & 53 & $13(24.5)$ & $0.83(0.42-1.64)$ & .594 \\
\hline Recessive & - & - & $0.37(0.09-1.59)$ & .181 & - & - & $0.75(0.37-1.49)$ & .407 & - & - & $0.71(0.37-1.37)$ & .305 \\
\hline \multicolumn{13}{|l|}{ rs1470383 } \\
\hline AA & 448 & $43(8.8)$ & 1.00 (Ref) & - & 449 & $110(24.5)$ & 1.00 (Ref) & - & 441 & $137(31.1)$ & 1.00 (Ref) & - \\
\hline AG & 175 & $14(8)$ & $0.8(0.42-1.51)$ & .490 & 176 & $43(24.4)$ & $1.02(0.68-1.54)$ & .921 & 174 & $50(28.7)$ & $0.91(0.61-1.34)$ & .629 \\
\hline GG & 22 & $1(4.6)$ & $0.43(0.06-3.31)$ & .416 & 23 & $13(56.5)$ & $4.10(1.73-9.71)$ & $.001^{\mathrm{d}}$ & 22 & $13(59.1)$ & $3.28(1.34-8.02)$ & $.009^{d}$ \\
\hline Recessive & - & - & $0.45(0.06-3.5)$ & .448 & - & - & $4.08(1.73-9.58)$ & $.001^{\mathrm{d}}$ & - & - & 3.37 (1.39-8.18) & $.007^{\mathrm{d}}$ \\
\hline \multicolumn{13}{|l|}{ rs3730581 } \\
\hline AA & 164 & $13(8.8)$ & 1.00 (Ref) & - & 165 & 39 (23.6) & 1.00 (Ref) & - & 117 & $45(27.8)$ & 1.00 (Ref) & - \\
\hline$A G$ & 325 & $32(9.9)$ & $1.32(0.67-2.63)$ & .424 & 322 & $83(25.8)$ & $1.19(0.76-1.85)$ & .450 & 217 & $102(32.0)$ & $1.33(0.87-2.04)$ & .192 \\
\hline GG & 155 & $13(8.4)$ & $1.07(0.48-2.42)$ & .867 & 160 & $43(26.9)$ & $1.27(0.76-2.10)$ & . 344 & 103 & $52(33.6)$ & $1.42(0.87-2.32)$ & .159 \\
\hline Recessive & - & - & $0.89(0.46-1.71)$ & .718 & - & - & $1.13(0.75-1.7)$ & .562 & - & - & $1.18(0.79-1.74)$ & .422 \\
\hline \multicolumn{13}{|l|}{ rs3730635 } \\
\hline AA & 624 & $57(8.8)$ & 1.00 (Ref) & - & 628 & $162(25.8)$ & 1.00 (Ref) & - & 617 & $195(31.6)$ & 1.00 (Ref) & - \\
\hline$A G$ & 21 & $1(4.8)$ & $0.54(0.07-4.17)$ & .554 & 20 & $4(20.0)$ & $0.71(0.23-2.19)$ & .554 & 20 & $5(25.0)$ & $0.73(0.26-2.08)$ & .561 \\
\hline
\end{tabular}

Data presented as $n(\%)$, unless otherwise noted.

Abbreviations: $\mathrm{Cl}=$ confidence interval; $\mathrm{NA}=$ not applicable; $\mathrm{OR}=$ odds ratio; Ref $=$ reference; $\mathrm{SNP}=$ single nucleotide polymorphism.

${ }^{a}$ Adjusted for sex.

Adjusted for sex.
bAdjusted for chemotherapy regimen.

${ }^{\mathrm{c} A d j u s t e d ~ f o r ~ s e x ~ a n d ~ c h e m o t h e r a p y ~ r e g i m e n . ~}$

dStatistically significant. 
Table 3 Association Between MDM2 SNPS and NSCLC Overall Survival and Progression-Free Survival

OS

PFS

\begin{tabular}{|c|c|c|c|c|c|c|c|c|c|}
\hline \multirow[b]{2}{*}{ Genotype } & \multirow[b]{2}{*}{ Patients (n) } & \multicolumn{4}{|c|}{ OS } & \multicolumn{4}{|c|}{ PFS } \\
\hline & & MST (mo) & Log-Rank $P$ & HR $\left(95 \%\right.$ CI) ${ }^{a}$ & $P$ Value ${ }^{a}$ & MST (mo) & Log-Rank $P$ & HR $(95 \%$ Cl) & $P$ Value $^{\mathrm{b}}$ \\
\hline rs3730488 & & & .096 & & & & .891 & & \\
\hline AA & 613 & 18.7 & - & 1.00 (Ref) & - & 6.4 & - & 1.00 (Ref) & - \\
\hline$A C$ & 48 & 13.3 & - & $1.35(0.98-1.88)$ & .070 & 7 & - & $1.06(0.75-1.51)$ & .741 \\
\hline CC & 1 & 13.4 & - & $2.74(0.38-19.73)$ & .316 & 7.6 & - & $0.97(0.14-6.95)$ & .974 \\
\hline Recessive & - & 13.4 versus 18.4 & .418 & $2.66(0.37-19.12)$ & .331 & 7.6 versus 6.5 & .897 & $0.97(0.13-6.93)$ & .972 \\
\hline rs1690924 & & & .114 & & & & .339 & & \\
\hline AA & 340 & 18.7 & - & 1.00 (Ref) & - & 5.5 & - & 1.00 (Ref) & - \\
\hline$A G$ & 269 & 16.9 & - & $1.08(0.89-1.31)$ & .418 & 6.9 & - & $0.92(0.76-1.12)$ & .426 \\
\hline GG & 54 & 22.3 & - & $0.74(0.51-1.06)$ & .095 & 7 & - & $0.76(0.53-1.09)$ & .137 \\
\hline Recessive & - & 22.3 versus 17.8 & .056 & $0.71(0.50-1.01)$ & .056 & 7.0 versus 6.2 & .259 & $0.79(0.55-1.12)$ & .183 \\
\hline rs1470383 & & & .382 & & & & .778 & & \\
\hline AA & 460 & 18.9 & - & 1.00 (Ref) & - & 6.8 & - & 1.00 (Ref) & - \\
\hline$A G$ & 180 & 17.2 & - & $1.18(0.96-1.44)$ & .124 & 5.5 & - & $1.08(0.88-1.34)$ & .456 \\
\hline GG & 23 & 12.4 & - & $1.20(0.72-2.00)$ & .474 & 4.4 & - & $1.13(0.66-1.93)$ & .663 \\
\hline Recessive & - & 12.4 versus 18.6 & .536 & $1.15(0.70-1.90)$ & .587 & 4.4 versus 6.5 & .618 & $1.10(0.65-1.88)$ & .725 \\
\hline rs3730581 & & & .766 & & & & .252 & & \\
\hline AA & 167 & 17.7 & - & 1.00 (Ref) & - & 5.8 & - & 1.00 (Ref) & - \\
\hline$A G$ & 334 & 18.8 & - & $0.99(0.79-1.24)$ & .917 & 6.5 & - & $1.00(0.80-1.25)$ & .999 \\
\hline$G G$ & 161 & 17.2 & - & $0.92(0.71-1.19)$ & .507 & 6.8 & - & $0.83(0.63-1.08)$ & .156 \\
\hline Recessive & - & 17.2 versus 18.6 & .478 & $0.92(0.75-1.14)$ & .464 & 6.8 versus 6.0 & .106 & $0.82(0.66-1.03)$ & .823 \\
\hline rs3730635 & & & $.036^{\mathrm{c}}$ & & & & .444 & & \\
\hline AA & 642 & 17.8 & - & 1.00 (Ref) & - & 6.5 & - & 1.00 (Ref) & - \\
\hline$A G$ & 21 & 29.5 & - & $0.54(0.29-1.01)$ & .052 & 6.2 & - & $0.82(0.50-1.35)$ & .428 \\
\hline \multicolumn{10}{|c|}{$\begin{array}{l}\text { Haplotype analysis of SNPs (rs1690924, } \\
\text { rs1470383, and rs3730581) in same block }\end{array}$} \\
\hline AAA & 666 & 18.6 & - & - & - & 6 & - & 1.00 (Ref) & - \\
\hline GAG & 375 & 18.8 & .394 & $0.93(0.80-1.09)$ & .372 & 7 & .098 & $0.87(0.75-1.02)$ & .083 \\
\hline AGG & 226 & 16.5 & .372 & $1.09(0.91-1.30)$ & .332 & 5.4 & .975 & $1.02(0.85-1.22)$ & .872 \\
\hline$A A G$ & 55 & 24 & $.038^{\mathrm{C}}$ & $0.66(0.46-0.95)$ & .025 & 6.9 & .123 & $0.79(0.56-1.11)$ & .167 \\
\hline Other & 4 & 15.8 & .204 & $2.15(0.80-5.79)$ & .129 & 6.3 & .448 & $1.35(0.50-3.62)$ & .556 \\
\hline
\end{tabular}

Data presented as $n(\%)$, unless otherwise noted.

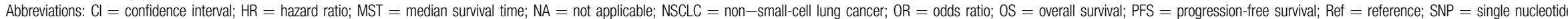
polymorphism.

${ }^{2}$ Adjusted for age, sex, TNM stage, and histologic type.

${ }^{\mathrm{b} A d j u s t e d ~ f o r ~ a g e, ~ s e x, ~ a n d ~ p e r f o r m a n c e ~ s t a t u s . ~}$

Statistically significant. 
Figure 2 Kaplan-Meier Curves of Overall Survival by Genotype of (A) rs3730635 in All Patients; (B) rs3730488 in Patients With Severe Overall Toxicity; (C) rs1690924 in Patients With Severe Hematologic Toxicity; (D) rs1470383 in Patients Without Severe Overall Toxicity; (E) rs1470383 in Patients Without Severe Hematologic Toxicity; (F) rs3730635 in Patients Without Severe Hematologic Toxicity
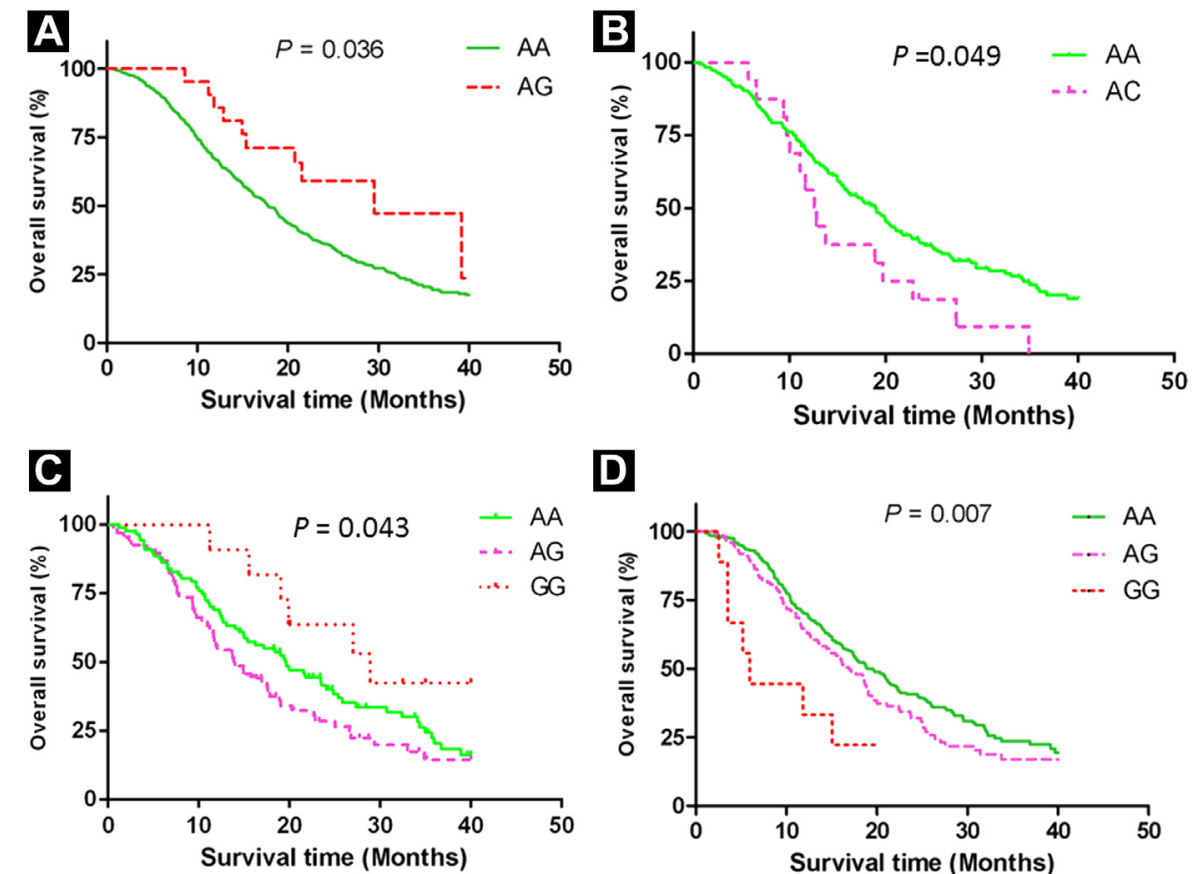

D

$\mathbf{E}$

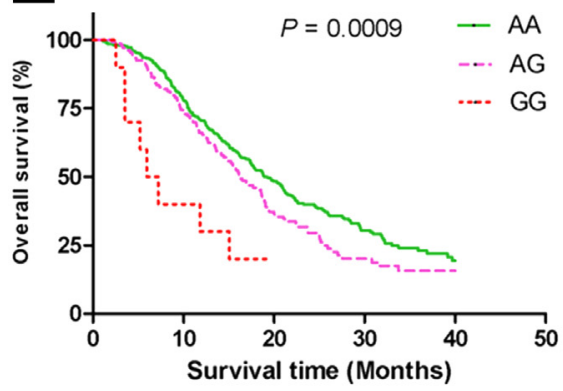

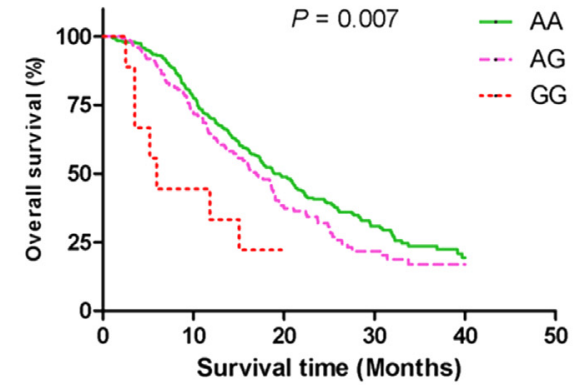

$\mathbf{F}$

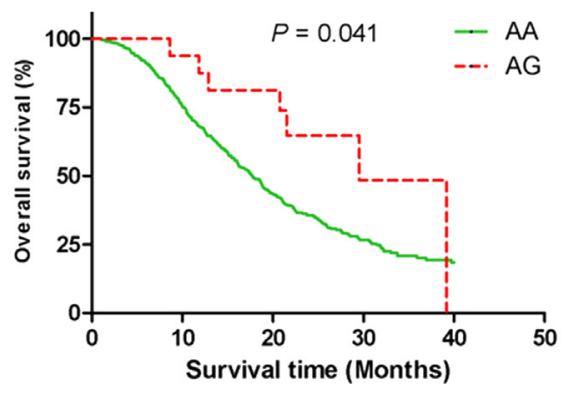

overall toxicity but who carried 1 or 2 variant alleles became worse (median OS time, 19.6 vs. 16.9 vs. 5.9 months; HR, 1.39; 95\% CI, 1.11-1.75; $P=.004)$. Similar results were found for patients without hematologic toxicity (HR, 1.44; 95\% CI, 1.17-1.79; $P=.0009)$. In addition, improved survival was found for patients without hematologic toxicity but who carried the AG genotype of rs3730635 compared with the survival of those with the AA genotype (median OS time, 17.7 vs. 29.5 months; HR, 0.45; 95\% CI, 0.21-0.96; $P=.041)$.

We also investigated the association of SNP rs1470383 with hematologic toxicity stratified by different clinical characteristics (ie, age, sex, smoking status, performance status, stage, and histologic type). Female patients, those aged $<58$ years, nonsmokers, patients with an Eastern Cooperative Oncology Group performance status of 0 to 1 , TNM stage IV, or adenocarcinoma, and those with the GG genotype were more sensitive to hematologic toxicity than were those with the wild-type homozygous AA genotype (Supplemental Table 3; available in the online version).

The FPRPS at different prior probability levels are summarized in Supplemental Table 4 (available in the online version). When the prior probability was assumed to be 0.1 and the prior effect size to be 2.5 and 1.5 for SNPs for platinum toxicities and OS, 4 associations were still considered noteworthy findings, because the probability of false-positive results was $<0.2$ : the association of rs 1470383 with hematologic toxicity and overall toxicity in patients without hematologic or overall toxicity and the association between rs1690924 and gastrointestinal toxicity.

Because no previously reported SNPs were included in the present study, we evaluated the LD between these reported SNPs in MDM2 and the 5 tagSNPs of the present study (Supplemental Figure 3; available in the online version). Their association with cancer risk or survival has been reported for 7 common SNPs. ${ }^{18,22-29}$ 
Table 4 Association Between MDM2 SNPS and NSCLC Overall Survival Stratified by Chemotherapy Toxicity

\begin{tabular}{|c|c|c|c|c|c|c|c|}
\hline SNP & Genotype & Stratification Factor & Patients (n) & MST (mo) & $\mid$ Log-Rank $P$ & HR $(95 \% \mathrm{CI})^{\mathrm{a}}$ & $P$ Value $^{\mathrm{a}}$ \\
\hline \multirow[t]{9}{*}{ rs3730488 } & CC/AC/AA & Overall toxicity & & & & & \\
\hline & & Absent & 1/26/409 & 13.4/13.3/18.7 & .532 & $1.19(0.77-1.82)$ & .432 \\
\hline & & Present & NA/16/184 & $N A / 12.7 / 19.0$ & $.049^{b}$ & $1.55(0.90-2.66)$ & .114 \\
\hline & & Gastrointestinal toxicity & & & & & \\
\hline & & Absent & $1 / 37 / 548$ & 13.4/13.7/18.7 & .291 & $1.28(0.89-1.82)$ & .183 \\
\hline & & Present & $\mathrm{NA} / 5 / 53$ & NA/12.6/18.8 & .134 & $2.16(0.80-5.79)$ & .127 \\
\hline & & Hematologic toxicity & & & & & \\
\hline & & Absent & $1 / 29 / 451$ & 13.4/13.4/18.6 & .485 & $1.21(0.81-1.81)$ & .359 \\
\hline & & Present & $N A / 15 / 151$ & NA/12.6/18.4 & .078 & $1.50(0.85-1.64)$ & .160 \\
\hline \multirow[t]{9}{*}{ rs1690924 } & $\mathrm{GG} / \mathrm{AG} / \mathrm{AA}$ & Overall toxicity & & & & & \\
\hline & & Absent & 40/163/234 & $22.3 / 18.0 / 17.7$ & .411 & $0.91(0.76-1.09)$ & .284 \\
\hline & & Present & 13/91/96 & 27.0/15.7/19.7 & .155 & $1.01(0.78-1.31)$ & .915 \\
\hline & & Gastrointestinal toxicity & & & & & \\
\hline & & Absent & 20/225/312 & 28.9/17.6/18.6 & .120 & $0.92(0.80-1.08)$ & .295 \\
\hline & & Present & $2 / 35 / 21$ & 18.3/15.7/19.9 & .960 & $0.78(0.41-1.49)$ & .457 \\
\hline & & Hematologic toxicity & & & & & \\
\hline & & Absent & 43/192/247 & 22.2/17.8/17.8 & .527 & $0.93(0.79-1.09)$ & .365 \\
\hline & & Present & $11 / 68 / 87$ & 28.9/13.9/19.5 & $.043^{b}$ & $1.02(0.77-1.34)$ & .905 \\
\hline \multirow[t]{9}{*}{ rs1470383 } & $\mathrm{GG} / \mathrm{AG} / \mathrm{AA}$ & Overall toxicity & & & & & \\
\hline & & Absent & $9 / 124 / 304$ & 5.9/16.9/19.6 & $.007^{\mathrm{b}}$ & $1.39(1.11-1.75)$ & $.004^{b}$ \\
\hline & & Present & $13 / 50 / 137$ & 25.8/17.6/18.9 & .626 & $0.90(0.69-1.19)$ & .459 \\
\hline & & Gastrointestinal toxicity & & & & & \\
\hline & & Absent & $21 / 161 / 405$ & $12.4 / 17.7 / 19.0$ & .478 & $1.13(0.94-1.35)$ & .193 \\
\hline & & Present & $1 / 14 / 43$ & NA/15.1/18.8 & .163 & $1.09(0.60-1.98)$ & .788 \\
\hline & & Hematologic toxicity & & & & & \\
\hline & & Absent & 10/133/339 & 6.6/16.2/19.3 & $.0009^{b}$ & $1.44(1.17-1.79)$ & $.0008^{b}$ \\
\hline & & Present & $13 / 43 / 130$ & 25.8/18.4/16.2 & .409 & $0.83(0.62-1.11)$ & .210 \\
\hline \multirow[t]{9}{*}{ rs3730581 } & GG/AG/AA & Overall toxicity & & & & & \\
\hline & & Absent & |03/217/117 & 18.6/18.7/17.7 & .920 & $0.98(0.83-1.15)$ & .772 \\
\hline & & Present & $52 / 102 / 45$ & 17.4/19.0/15.0 & .556 & $0.93(0.73-1.17)$ & .520 \\
\hline & & Gastrointestinal toxicity & & & & & \\
\hline & & Absent & 142/293/151 & 18.6/18.8/17.7 & .499 & $0.93(0.81-1.06)$ & .274 \\
\hline & & Present & $13 / 32 / 13$ & 15.3/20.0/12.6 & .552 & $0.98(0.58-1.64)$ & .923 \\
\hline & & Hematologic toxicity & & & & & \\
\hline & & Absent & |117/239/126 & 16.1/18.8/17.8 & .971 & $1.01(0.87-1.18)$ & .863 \\
\hline & & Present & $43 / 83 / 39$ & 17.8/18.9/15.0 & .243 & $0.87(0.68-1.12)$ & .267 \\
\hline \multirow[t]{9}{*}{ rs3730635 } & $\mathrm{AG} / \mathrm{AA}$ & Overall toxicity & & & & & \\
\hline & & Absent & $15 / 422$ & 29.5/17.8 & .070 & $0.49(0.23-1.04)$ & .064 \\
\hline & & Present & $5 / 195$ & $15.4 / 18.0$ & .777 & $0.96(0.30-3.03)$ & .941 \\
\hline & & Gastrointestinal toxicity & & & & & \\
\hline & & Absent & $20 / 567$ & 29.5/18.4 & .069 & $0.58(0.31-1.09)$ & .091 \\
\hline & & Present & $1 / 57$ & $\mathrm{NA} / 16$ & NA & NA & NA \\
\hline & & Hematologic toxicity & & & & & \\
\hline & & Absent & $16 / 466$ & $29.5 / 17.7$ & $.041^{b}$ & $0.45(0.21-0.96)$ & $.039^{b}$ \\
\hline & & Present & $4 / 162$ & $15.2 / 18.4$ & .870 & $1.18(0.37-3.77)$ & .779 \\
\hline
\end{tabular}

Data presented as number of patients with each genotype, unless otherwise noted.

Abbreviations: $\mathrm{Cl}=$ confidence interval; $\mathrm{HR}=$ hazard ratio; $\mathrm{MST}=$ median survival time; NA $=$ not applicable; NSCLC $=$ non-small-cell lung cancer; SNP $=$ single nucleotide polymorphism.

${ }^{a}$ Adjusted for age, sex, TNM stage, and histologic type.

${ }^{b}$ Statistically significant. 


\section{MDM2 SNPs Predict Toxicities and Survival in Advanced NSCLC}

Except for 1 indel variant (rs3730485, which was not included in the 1000 genome data), all other 6 reported SNPs had high LD ( $\mathrm{r} 2>$ 0.8 ), with 2 tagSNPs in the present study, with rs1690924 tagging 4 SNPs (rs937283, rs937282, rs1144944, and rs1690916), and rs3730581 tagging 2 other SNPs (rs3730536 and rs2279744).

\section{Discussion}

In the present study, we evaluated the association of 5 tagging SNPs in the MDM2 gene with chemotherapy toxicity and clinical outcomes (OS and PFS) in patients with advanced NSCLC treated with platinum-based regimens. Our results revealed that multiple SNPs in MDM2 could influence the occurrence of severe chemotherapy toxicity (rs1470383 and rs1690924) and survival outcome (rs3730635) independently. In addition, 2 SNPs (rs1470383 and rs3730635) had significant effects on OS for patients without hematologic or overall toxicity. These results suggest that MDM2 SNPs might have significant prognostic effects in patients with advanced NSCLC treated with first-line platinum-based chemotherapy.

The susceptibility to chemotherapy toxicity varies among patients, making it a major consideration for personalized treatment planning. The identification of related genetic markers would be helpful for screening patients at high risk of chemotherapy toxicity and to develop suitable treatment plans. ${ }^{30}$ A series of studies have been performed to identify the genetic variants associated with toxicity susceptibility at different levels. Several genome-wide studies screened the association between SNPs and platinum susceptibility on a genome scale and identified multiple associated loci (eg, SNPs in DAPK3 and METTL6) using the lymphoblastoid cell lines from the International HapMap project. ${ }^{31-33}$ However, such studies using cell lines could not replicate the findings from population-based studies, which had reported significant associations between SNPs in multiple genes (eg, drug metabolism genes, DNA repair genes, and apoptosis genes) and the toxicity response. ${ }^{34-37}$ This difference might have resulted from different mechanisms underlying the toxicity responses of the 2 levels (cell line and individual).

The p53 pathway plays important roles in chemotherapy response and cancer progression. ${ }^{38,39}$ As a key negative regulator of $\mathrm{p} 53, \mathrm{MDM} 2$ is a potential predictive marker for treatment toxicity and survival. The association between the functional SNP T309G (rs2279744) and platinum-based or non-platinum-based chemotherapy responses has been investigated in many cancers. $^{18,35,40-43}$ However, the results have been inconsistent regarding the effects of this SNP on gastrointestinal and hematologic toxicities. No significant effects were found in 136 patients with bladder cancer who received combined cisplatinbased systemic chemotherapy and radiotherapy. ${ }^{35}$ One recent study observed a significant association between severe hematologic and overall toxicities and SNP309 in 444 patients with advanced NSCLC treated with platinum-based chemotherapy. ${ }^{18}$ Although this SNP was not included in our study, one of its high LD SNP rs3730581 (pairwise LD $\mathrm{r}^{2}=0.86$ ), had been investigated but did not show a significant effect on any chemotherapy toxicity. That study also found that the GC heterozygotes of another functional SNP rs937282 had a greater incidence of severe gastrointestinal toxicity than did the homozygotes. This was confirmed by our finding that the heterozygous genotype of its high LD SNP rs1690924 ( $\mathrm{r} 2=0.91$ ) was significantly associated with an increased risk of gastrointestinal toxicity.

Our study also found that another SNP rs1470383 had a significant association with an increased incidence of severe hematologic toxicity and overall toxicity. Additional stratification analysis revealed that this SNP only influenced the OS of patients without any toxicity. This patient subgroup also had a relatively lower partial response rate, indicating less sensitivity to chemotherapy. Taken together, these results suggest that the effect of this SNP on survival was modified by treatment efficiency. However, this SNP did not have a clear function. In silica prediction using FSNP (available at: http://compbio.cs.queensu.ca/F-SNP) showed that this SNP could alter the binding activity of transcript factors (eg, GATA-2/3). ${ }^{44}$ LD analysis with SNPinfo showed it also had a low $\mathrm{LD}\left(\mathrm{r} 2=0.32, \mathrm{D}^{\prime}=0.79\right)$ with 2 other potential functional SNPs (rs2431655 and rs2259588, located at the transcription factor binding site and exonic splicing enhancer, respectively) in the Asian population. Additional studies are warranted to validate our findings and reveal the underlying mechanism of such associations.

The association between SNP T309G and the survival of patients with NSCLC has been investigated in previous studies. Consistent results were reported on the association between this SNP and worse survival in patients with early-stage NSCLC. ${ }^{45,46}$ However, for advanced NSCLC, the prognostic effect of this SNP remains controversial. ${ }^{18,47-50}$ Three studies had reported a significant association between SNP T309G and unfavorable survival in patients with advanced NSCLC, ${ }^{47,48}$ but 2 other studies did not support the association. ${ }^{49,50}$ Based on the results of its high LD SNP rs3730581, our study results were was consistent with those from the latter study. Recently, genome-wide studies were conducted to investigate the association of SNPs with OS in patients with advanced NSCLC; however, no significant association was reported for SNPs in MDM2. ${ }^{51-55}$ These results suggested that SNPs in MDM2 might have only limited effects on the survival of patients with advanced NSCLC. The inconsistencies among different studies might have resulted from the heterogeneity among the studies (eg, different tumor cell grade of differentiation, smoking cessation, dietary supplements, or genetic variations). ${ }^{56}$

Never smokers with NSCLC have been defined as a separate population, because they have unique clinical and molecular characteristics. ${ }^{57}$ More than one half of the female patients with NSCLCs will be never smokers in the Asian population. ${ }^{58}$ One additional finding of that study was that female patients and never smokers tended to have a significantly high risk of gastrointestinal toxicity. We also observed a nonsignificantly greater incidence of hematologic toxicity in these 2 populations than in males and smokers. From the results of previous studies, most of the toxic side effects of chemotherapy could be explained by the sensitivity of normal cells to drug-induced apoptosis. ${ }^{59}$ Thus, these tendencies might be because females and never smokers are more sensitive to chemotherapeutic drug-induced apoptosis than are males and smokers, because nicotine in tobacco could inhibit the induced apoptosis. $^{60}$

The present study had several limitations. First, although 2 SNPs in MDM2 were revealed to influence chemotherapy toxicity, 
the prediction models performed poorly, even after including the identified SNPs with the other clinical variables. This suggests that the current prediction models have very limited clinical application and additional genetic markers should be identified to improve the prediction accuracy. Second, the 5 tagging SNPs genotyped in the present study were located at introns, which do not have clear biologic functions. Although previous studies have shown that intronic SNPs do have the potential to affect gene function by producing alternative splicing or triggering microRNA arising, directed genotyping of these functional SNPs are warranted. Third, 1 tag SNP failed in genotyping, which influenced the coverage rate. Although the remaining 5 tagging SNPs still represented $93.8 \%$ (15 of 16) of the SNPs in MDM2, some real causal SNPs might have been missed. Additional explorations based on 1000 genome database are required in future studies. Finally, the present study only assessed gastrointestinal and hematologic toxicities and did not include the more typical, platinum-associated toxicities, such as nephrotoxicity and ototoxicity, limiting its clinical implications. More comprehensive chemotherapy-related toxicity assessments are needed in future studies.

\section{Conclusion}

The present study identified several SNPs in MDM2 that had a significant association with chemotherapy toxicities and clinical outcomes in patients with advanced NSCLC. These SNPs have the potential to be used as genetic markers to predict the toxic response to platinum-based chemotherapy and OS in patients with advanced NSCLC. Additional population studies and functional validations of our findings are warranted.

\section{Clinical Practice Points}

- Platinum-based doublet regimens are widely used as first-line treatment of patients with advanced NSCLC and lead to improved survival outcome.

- However, a number of patients who receive platinum-based treatment will develop high-grade toxicities, which might decrease treatment efficiency or cause therapy withholding.

- Identification of the inherited variants associated with platinumbased therapy toxicity and outcomes will be useful in developing suitable individualized treatment plans.

- The association between SNPs in MDMs and OS of lung cancer has been investigated in several studies.

- However, until now, little has been known about the effect of MDM2 SNPs on the chemotherapy toxicities of patients with advanced NSCLC.

- In the present study, we selected 5 tagging SNPs in MDM2 to evaluate their associations with chemotherapy toxicity and clinical outcomes in 663 patients with advanced NSCLC who had received first-line platinum-based chemotherapy.

- The results revealed that 2 SNPs (rs1470383 and rs1690924) had significant associations with chemotherapy-related toxicities.

- One SNP rs1470383 also influenced the OS of patients without overall toxicity or hematologic toxicity.

- These findings could be used as genetic markers to screen susceptible patients who are sensitive to platinum-based chemotherapy.

\section{Acknowledgments}

This work was supported in part by the National Basic Research Program (973 program) of China (grant 2011CB503802); Shanghai Science and Technology Research Program (grants 09JC1402200 and 10410709100); National Natural Science Foundation of China (grants 30800622, 81001114, 81172093, and 30890034); the Shanghai Pujiang Program (grant 11PJD005); China Ministry of Health (grant 201002007); and the Shanghai Leading Academic Discipline Project (grant B111).

\section{Disclosure}

The authors have stated that they have no conflicts of interest.

\section{Supplemental Data}

Supplemental figures and tables accompanying this article can be found in the online version at http://dx.doi.org/10.1016/j.cllc. 2015.02.001.

\section{References}

1. Jemal A, Bray F, Center MM, Ferlay J, Ward E, Forman D. Global cancer statistics. CA Cancer I Clin 2011; 61:69-90.

2. Goffin J, Lacchetti C, Ellis PM, Ung YC, Evans WK, Lung Cancer Disease Site Group of Cancer Care Ontario's Program in Evidence-Based Care. First-line systemic chemotherapy in the treatment of advanced non-small cell lung cancer: a systematic review. I Thorac Oncol 2010; 5:260-74.

3. Gonzalez VM, Fuertes MA, Alonso C, Perez JM. Is cisplatin-induced cell death always produced by apoptosis? Mol Pharmacol 2001; 59:657-63.

4. Jin S, Levine AJ. The p53 functional circuit. J Cell Sci 2001; 114:4139-40.

5. Michael D, Oren M. The p53-MDM2 module and the ubiquitin system. Semin Cancer Biol 2003; 13:49-58.

6. Rayburn E, Zhang R, He J, Wang H. MDM2 and human malignancies: expression, clinical pathology, prognostic markers, and implications for chemotherapy. Curr Cancer Drug Targets 2005; 5:27-41.

7. Onel K, Cordon-Cardo C. MDM2 and prognosis. Mol Cancer Res 2004; 2:1-8.

8. Higashiyama M, Doi O, Kodama K, et al. MDM2 gene amplification and expression in non-small-cell lung cancer: immunohistochemical expression of its protein is a favourable prognostic marker in patients without p53 protein accumulation. Br I Cancer 1997; 75:1302-8.

9. Ko JL, Cheng YW, Chang SL, Su JM, Chen CY, Lee H. MDM2 mRNA expression is a favorable prognostic factor in non-small-cell lung cancer. Int $J$ Cancer 2000; 89:265-70.

10. Wang YC, Lin RK, Tan YH, Chen JT, Chen CY, Wang YC. Wild-type p53 overexpression and its correlation with MDM2 and p14ARF alterations: an alternative pathway to non-small-cell lung cancer. J Clin Oncol 2005; 23:154-64.

11. Shastry BS. SNPs: impact on gene function and phenotype. Methods Mol Biol 2009; 578:3-22

12. Bond GL, Hu W, Bond EE, et al. A single nucleotide polymorphism in the MDM2 promoter attenuates the p53 tumor suppressor pathway and accelerates tumor formation in humans. Cell 2004; 119:591-602.

13. Knappskog S, Bjornslett M, Myklebust LM, et al. The MDM2 promoter SNP285C/309G haplotype diminishes Sp1 transcription factor binding and reduces risk for breast and ovarian cancer in Caucasians. Cancer Cell 2011; 19:273-82.

14. Ryan BM, Calhoun KM, Pine SR, et al. MDM2 SNP285 does not antagonize the effect of SNP309 in lung cancer. Int J Cancer 2012; 131:2710-6.

15. Lind H, Zienolddiny S, Ekstrom PO, Skaug V, Haugen A. Association of a functional polymorphism in the promoter of the MDM2 gene with risk of nonsmall cell lung cancer. Int I Cancer 2006; 119:718-21.

16. Knappskog S, Trovik J, Marcickiewicz J, et al. SNP285C modulates oestrogen receptor/Sp1 binding to the MDM2 promoter and reduces the risk of endometrial but not prostatic cancer. Eur I Cancer 2012; 48:1988-96.

17. Shinohara A, Sakano S, Hinoda Y, et al. Association of TP53 and MDM2 polymorphisms with survival in bladder cancer patients treated with chemoradiotherapy. Cancer Sci 2009; 100:2376-82.

18. Zheng D, Chen Y, Gao C, et al. Polymorphisms of p53 and MDM2 genes are associated with severe toxicities in patients with non-small cell lung cancer. Cancer Biol Ther 2014; 15:1542-51.

19. Zhao X, Wang X, Wu W, et al. Matrix metalloproteinase-2 polymorphisms and clinical outcome of Chinese patients with nonsmall cell lung cancer treated with first-line, platinum-based chemotherapy. Cancer 2012; 118:3587-98.

20. Barrett JC, Fry B, Maller J, Daly MJ. Haploview: analysis and visualization of LD and haplotype maps. Bioinformatics 2005; 21:263-5.

21. Wacholder S, Chanock S, Garcia-Closas M, El Ghormli L, Rothman N. Assessing the probability that a positive report is false: an approach for molecular epidemiology studies. J Natl Cancer Inst 2004; 96:434-42. 


\section{MDM2 SNPs Predict Toxicities and Survival in Advanced NSCLC}

22. Yang J, Liu B, Li W, et al. Association of 553 and MDM2 polymorphisms with risk of human papillomavirus (HPV)-related esophageal squamous cell carcinoma (ESCC). Cancer Epidemiol 2013; 37:629-33.

23. Zhang F, Xu L, Wei Q, Song X, Sturgis EM, Li G. Significance of MDM2 and P14 ARF polymorphisms in susceptibility to differentiated thyroid carcinoma. Surgery 2013; 153:711-7.

24. Huang C, Liu W, Ji GX, et al. Genetic variants in TP53 and MDM2 associated with male infertility in Chinese population. Asian J Androl 2012; 14:691-4.

25. Dong D, Gao X, Zhu Z, Yu Q, Bian S, Gao Y. A 40-bp insertion/deletion polymorphism in the constitutive promoter of MDM2 confers risk for hepatocellular carcinoma in a Chinese population. Gene 2012; 497:66-70.

26. de Oliveira Reis AH, de Carvalho IN, de Sousa Damasceno PB, et al. Influence of MDM2 and MDM4 on development and survival in hereditary retinoblastoma. Pediatr Blood Cancer 2012; 59:39-43.

27. Chen X, Sturgis EM, Lei D, Dahlstrom K, Wei Q, Li G. Human papillomavirus seropositivity synergizes with MDM2 variants to increase the risk of oral squamous cell carcinoma. Cancer Res 2010; 70:7199-208.

28. Healy J, Bourgey M, Richer C, Sinnett D, Roy-Gagnon MH. Detection of fetomaternal genotype associations in early-onset disorders: evaluation of different methods and their application to childhood leukemia. J Biomed Biotechnol 2010; 2010:369534.

29. Canova C, Hashibe M, Simonato L, et al. Genetic associations of 115 polymorphisms with cancers of the upper aerodigestive tract across 10 European countries: the ARCAGE project. Cancer Res 2009; 69:2956-65.

30. Giovannetti E, Toffalorio F, De Pas T, Peters GJ. Pharmacogenetics of conventional chemotherapy in non-small-cell lung cancer: a changing landscape? Pharmacogenomics 2012; 13:1073-86.

31. Dolan ME, Newbold KG, Nagasubramanian R, et al. Heritability and linkage analysis of sensitivity to cisplatin-induced cytotoxicity. Cancer Res 2004; 64: 4353-6.

32. O'Donnell PH, Gamazon E, Zhang W, et al. Population differences in platinum toxicity as a means to identify novel genetic susceptibility variants. Pharmacogenet Genomics 2010; 20:327-37.

33. Tan XL, Moyer AM, Fridley BL, et al. Genetic variation predicting cisplatin cytotoxicity associated with overall survival in lung cancer patients receiving platinum-based chemotherapy. Clin Cancer Res 2011; 17:5801-11.

34. Han B, Gao G, Wu W, et al. Association of ABCC2 polymorphisms with platinum-based chemotherapy response and severe toxicity in non-small cell lung cancer patients. Lung Cancer 2011; 72:238-43.

35. Sakano S, Hinoda Y, Sasaki M, et al. Nucleotide excision repair gene polymorphisms may predict acute toxicity in patients treated with chemoradiotherapy for bladder cancer. Pharmacogenomics 2010; 11:1377-87.

36. Wu W, Zhang W, Qiao R, et al. Association of XPD polymorphisms with severe toxicity in non-small cell lung cancer patients in a Chinese population. Clin Cancer Res 2009; 15:3889-95.

37. Suk R, Gurubhagavatula S, Park S, et al. Polymorphisms in ERCC1 and grade 3 or 4 toxicity in non-small cell lung cancer patients. Clin Cancer Res 2005; 11 1534-8.

38. Breen L, Heenan M, Amberger-Murphy V, Clynes M. Investigation of the role of p53 in chemotherapy resistance of lung cancer cell lines. Anticancer Res 2007; 27: $1361-4$.

39. Mitsudomi T, Hamajima N, Ogawa M, Takahashi T. Prognostic significance of p53 alterations in patients with non-small cell lung cancer: a meta-analysis. Clin Cancer Res 2000; 6:4055-63.

40. Wang S, Chen L, Zhao Q, et al. Effect of TP53 codon 72 and MDM2 SNP309 polymorphisms on survival of gastric cancer among patients who receiving 5-fluorouracil-based postoperative adjuvant chemotherapy. Cancer Chemother Pharmacol 2013; 71:1073-82.

41. Ohnstad HO, Castro R, Sun J, et al. Correlation of TP53 and MDM2 genotypes with response to therapy in sarcoma. Cancer 2013; 119:1013-22.

42. Jamshidi M, Schmidt MK, Dork T, et al. Germline variation in TP53 regulatory network genes associates with breast cancer survival and treatment outcome. Int Cancer 2013; 132:2044-55.

43. Okishiro M, Kim SJ, Tsunashima R, et al. MDM2 SNP309 and TP53 R72P associated with severe and febrile neutropenia in breast cancer patients treated with 5-FU/epirubicin/cyclophosphamide. Breast Cancer Res Treat 2012; 132:947-53.

44. Lee PH, Shatkay H. F-SNP: computationally predicted functional SNPs for disease association studies. Nucleic Acids Res 2008; 36:D820-4.

45. Chien WP, Wong RH, Cheng YW, Chen CY, Lee H. Associations of MDM2 SNP309, transcriptional activity, mRNA expression, and survival in stage I nonsmall-cell lung cancer patients with wild-type p53 tumors. Ann Surg Oncol 2010; 17:1194-202.

46. Heist RS, Zhou W, Chirieac LR, et al. MDM2 polymorphism, survival, and histology in early-stage non-small-cell lung cancer. J Clin Oncol 2007; 25:2243-7.

47. Dong J, Ren B, Hu Z, et al. MDM2 SNP309 contributes to non-small cell lung cancer survival in Chinese. Mol Carcinog 2011; 50:433-8.

48. Han JY, Lee GK, Jang DH, Lee SY, Lee JS. Association of p53 codon 72 polymorphism and MDM2 SNP309 with clinical outcome of advanced nonsmall cell lung cancer. Cancer 2008; 113:799-807.

49. Chua HW, Ng D, Choo S, et al. Effect of MDM2 SNP309 and p53 codon 72 polymorphisms on lung cancer risk and survival among non-smoking Chinese women in Singapore. BMC Cancer 2010; 10:88.

50. Liu L, Wu C, Wang Y, et al. Combined effect of genetic polymorphisms in p53, p73, and MDM2 on non-small cell lung cancer survival. I Thorac Oncol 2011; 6 $1793-800$.

51. Sato Y, Yamamoto N, Kunitoh H, et al. Genome-wide association study on overall survival of advanced non-small cell lung cancer patients treated with carboplatin and paclitaxel. I Thorac Oncol 2011; 6:132-8.

52. Wu X, Ye Y, Rosell R, et al. Genome-wide association study of survival in nonsmall cell lung cancer patients receiving platinum-based chemotherapy. J Natl Cancer Inst 2011; 103:817-25.

53. Niu N, Schaid DJ, Abo RP, et al. Genetic association with overall survival of taxane-treated lung cancer patients — a genome-wide association study in human lymphoblastoid cell lines followed by a clinical association study. BMC Cancer 2012; 12:422.

54. Wu X, Wang L, Ye Y, et al. Genome-wide association study of genetic predictors of overall survival for non-small cell lung cancer in never smokers. Cancer Res 2013 73:4028-38.

55. Han JY, Lee YS, Shin ES, et al. A genome-wide association study of survival in small-cell lung cancer patients treated with irinotecan plus cisplatin chemotherapy. Pharmacogenomics J 2014; 14:20-7.

56. Molina JR, Yang P, Cassivi SD, Schild SE, Adjei AA. Non-small cell lung cancer epidemiology, risk factors, treatment, and survivorship. Mayo Clin Proc 2008; 83:584-94.

57. Stinchcombe TE, Socinski MA. Current treatments for advanced stage non-smal cell lung cancer. Proc Am Thorac Soc 2009; 6:233-41.

58. Samet JM, Avila-Tang E, Boffetta P, et al. Lung cancer in never smokers: clinical epidemiology and environmental risk factors. Clin Cancer Res 2009; 15:5626-45.

59. Johnstone RW, Ruefli AA, Lowe SW. Apoptosis: a link between cancer genetics and chemotherapy. Cell 2002; 108:153-64.

60. Dasgupta P, Kinkade R, Joshi B, Decook C, Haura E, Chellappan S. Nicotine inhibits apoptosis induced by chemotherapeutic drugs by up-regulating XIAP and survivin. Proc Natl Acad Sci U S A 2006; 103:6332-7. 

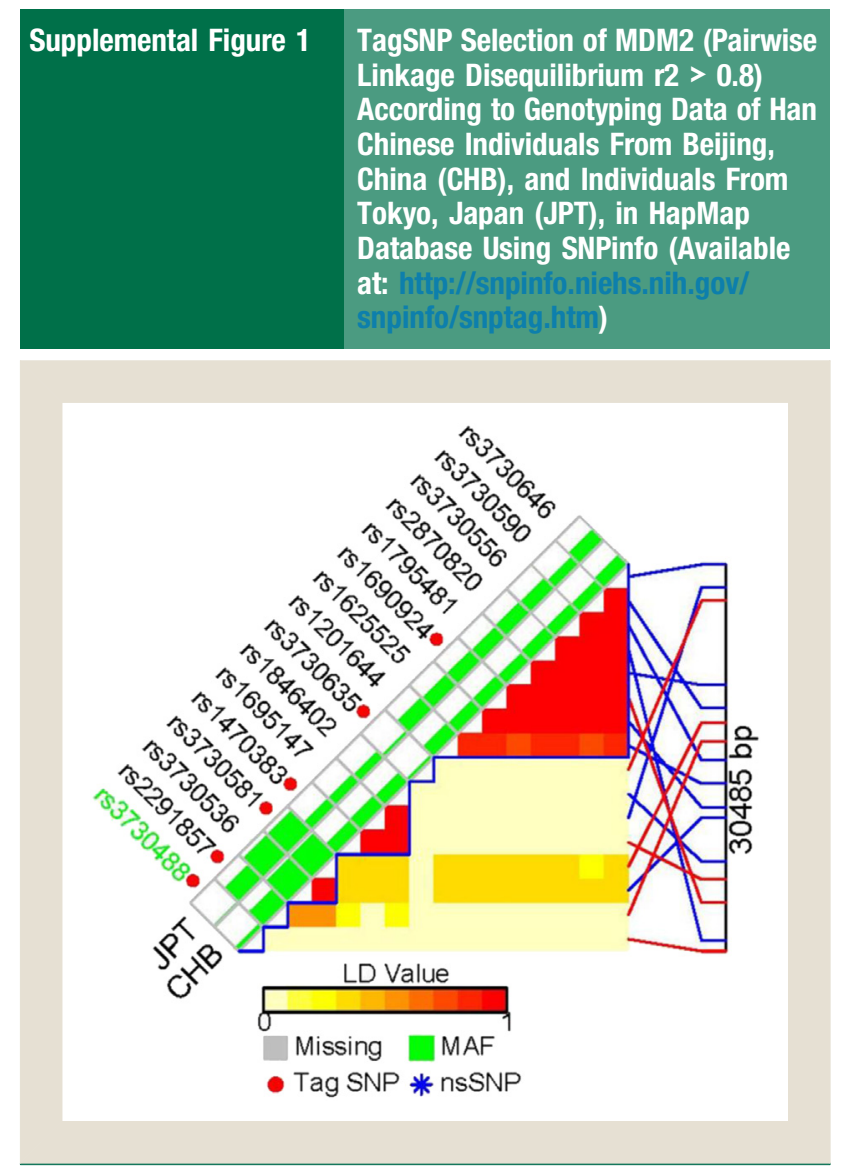

Abbreviations: $L D=$ linkage disequilibrium; MAF $=$ minor allele frequency; $S N P=$ single nucleotide polymorphism. 


\section{MDM2 SNPs Predict Toxicities and Survival in Advanced NSCLC}

\section{Supplemental Figure 2 \\ Receiver Operating Characteristic (ROC) Curve With and Without Single Nucleotide Polymorphisms in \\ Prediction Models of Chemotherapy-related Toxicity. (A) ROC Curve for Gastrointestinal Toxicity Prediction \\ $(P=.002)$. (B) ROC Curve for Hematologic Toxicity Prediction $(P=.103)$. (C) ROC Curve for Overall Toxicity Prediction ( $P=$.283). A Codominant Model Was Used for All SNPs in ROC Curve Estimation}
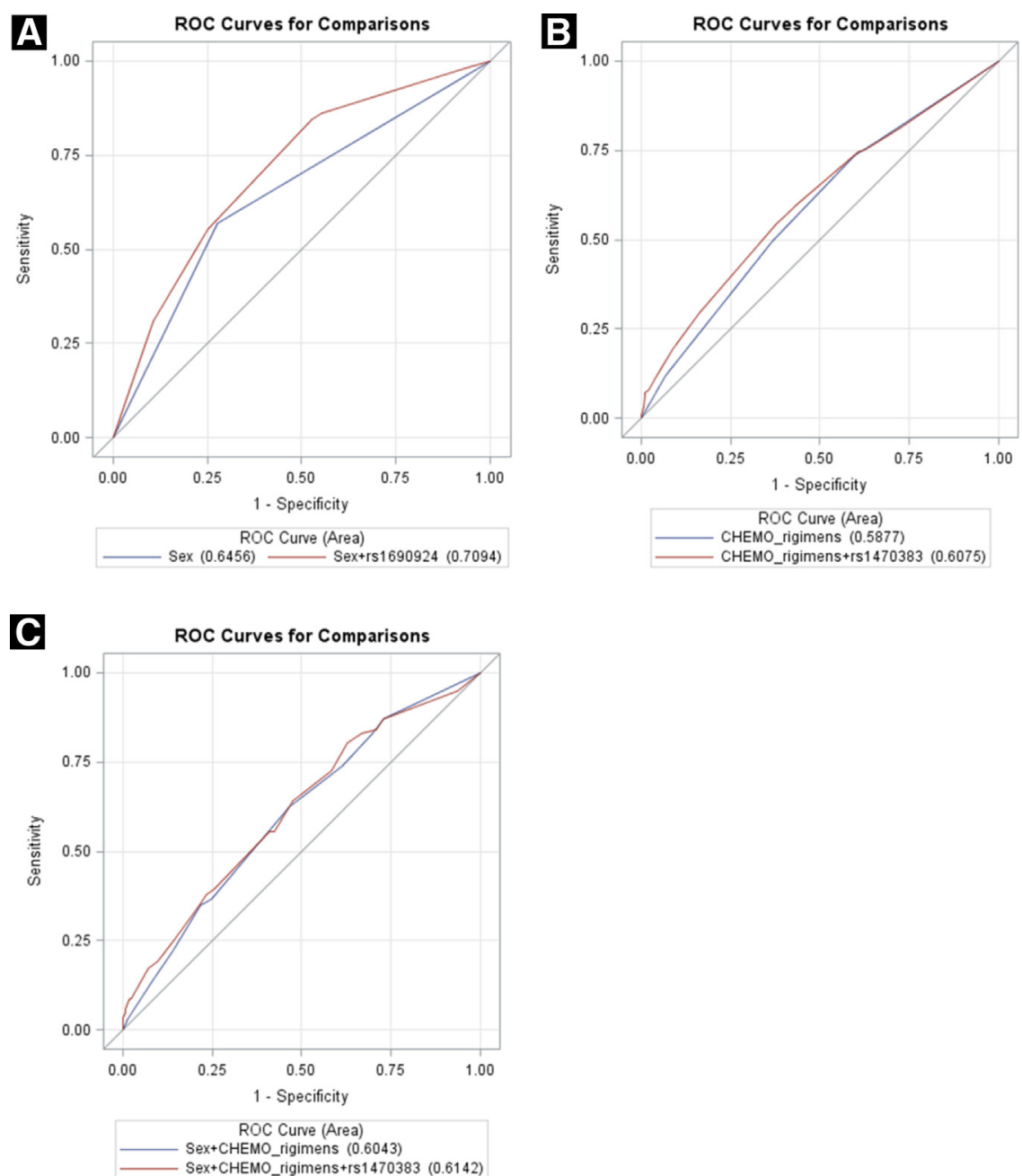

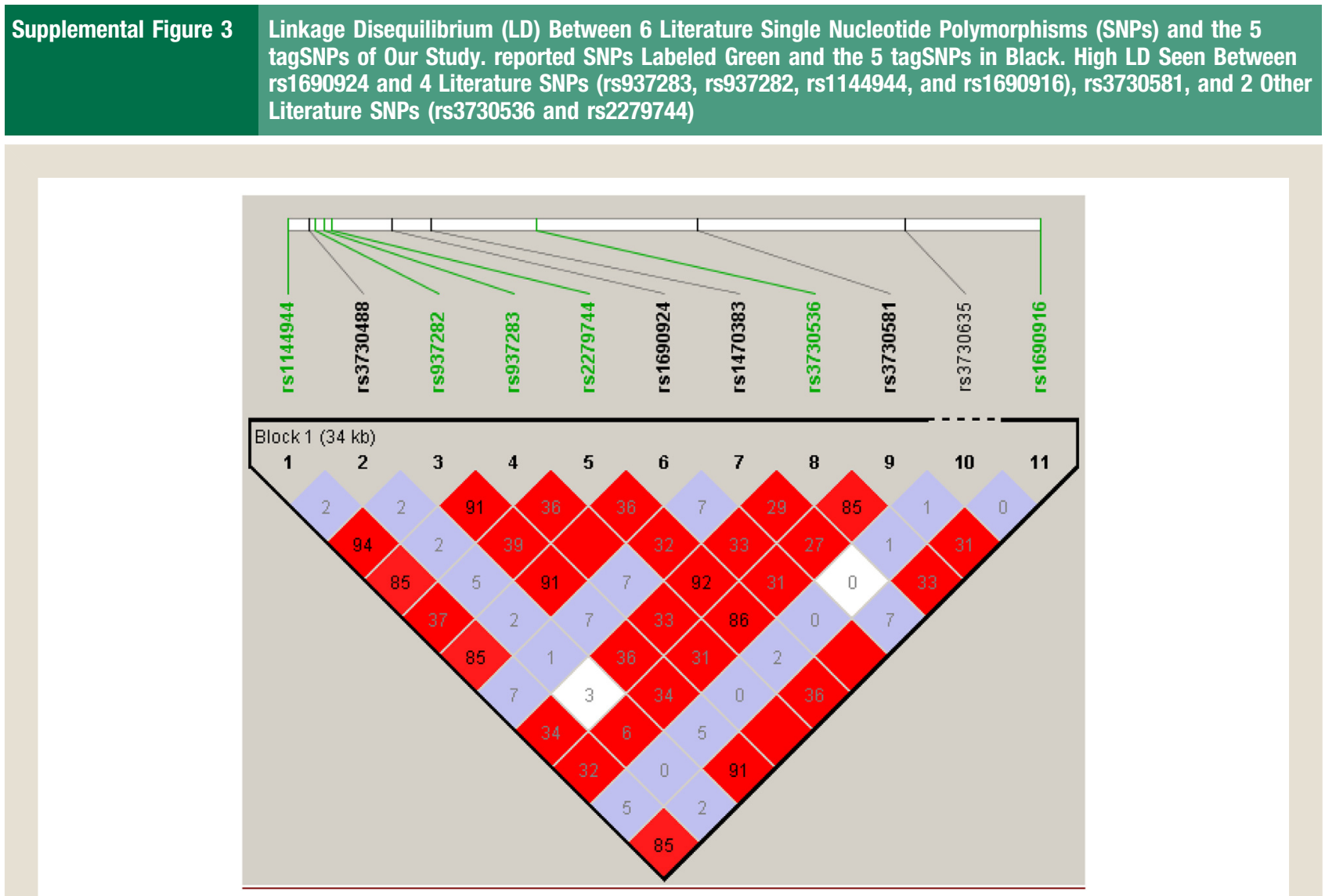

\section{Supplemental Table 1 Summary of Selected MDM2 SNPs in Present Study}

\begin{tabular}{|c|c|c|c|c|c|c|}
\hline \multirow[b]{2}{*}{ SNP } & \multirow[b]{2}{*}{ Position } & \multirow[b]{2}{*}{ Gene Location } & \multirow[b]{2}{*}{ Genotyping Rate (\%) } & \multicolumn{2}{|c|}{ MAF } & \multirow[b]{2}{*}{$P$ Value (HWE) } \\
\hline & & & & CHB & Our Study & \\
\hline rs3730488 & 69201496 & $5^{\prime}$ Near gene & 99.9 & 0.06 & 0.04 & .235 \\
\hline rs1690924 & 69205321 & Intron 2 & 100 & 0.19 & 0.28 & .693 \\
\hline rs1470383 & 69207162 & Intron 2 & 100 & 0.17 & 0.17 & .821 \\
\hline rs2291857 & 69218038 & Intron 3 & NA & 0.30 & NA & NA \\
\hline rs3730581 & 69219492 & Intron 3 & 99.9 & 0.43 & 0.49 & .157 \\
\hline rs3730635 & 69229123 & Intron 4 & 100 & 0.05 & 0.02 & .502 \\
\hline
\end{tabular}

Abbreviations: $\mathrm{CHB}=$ Han Chinese in Beijing; HWE $=$ Hardy-Weinberg equilibrium; MAF $=$ minor allele frequency; SNPs $=$ single nucleotide polymorphisms. aFailed in design. 
Supplemental Table 2 Association of Demographic and Clinical Variables With Overall Survival and Progression-Free Survival in Patients With Advanced NSCLC Treated With First-Line Platinum-Based Chemotherapy

\begin{tabular}{|c|c|c|c|c|c|c|c|c|c|c|c|c|}
\hline \multirow[b]{2}{*}{ Variable } & \multicolumn{6}{|c|}{ Overall Survival } & \multicolumn{6}{|c|}{ Progression-free Survival } \\
\hline & Patients (n) & Events (n) & $\begin{array}{l}\text { MST } \\
\text { (mo) }\end{array}$ & Log-Rank $P$ & HR (95\% Cl) & $P$ Value ${ }^{a}$ & Patients (n) & Events (n) & MST (mo) & Log-Rank $P$ & HR (95\% CI) & $P$ Value $^{\mathrm{a}}$ \\
\hline Sex & & & & .037 & & .879 & & & & .138 & & .511 \\
\hline Male & 465 & $336(72.3)$ & 17.2 & & 1.00 (Ref) & & 465 & $308(66.2)$ & 6.8 & & 1.00 (Ref) & \\
\hline Female & 197 & $130(66.0)$ & 20 & & $0.98(0.73-1.32)$ & & 197 & $141(71.6)$ & 5.8 & & $1.11(0.82-1.49)$ & \\
\hline Age (years) & & & & .107 & & .227 & & & & .445 & & .446 \\
\hline$\leq 58$ & 333 & $229(68.8)$ & 19.4 & & 1.00 (Ref) & & 333 & $235(70.6)$ & 5.9 & & 1.00 (Ref) & \\
\hline$>58$ & 237 & $237(72.0)$ & 16.8 & & $1.12(0.93-1.36)$ & & 329 & $214(65.0)$ & 7.1 & & $0.93(0.77-1.12)$ & \\
\hline Smoking status & & & & .034 & & .316 & & & & .171 & & .856 \\
\hline Never smokers & 275 & $183(66.5)$ & 19.5 & & 1.00 (Ref) & & 275 & $192(69.8)$ & 5.7 & & 1.00 (Ref) & \\
\hline Ever smokers & 386 & $283(73.3)$ & 16.9 & & $1.15(0.88-1.50)$ & & 386 & $256(66.3)$ & 6.9 & & $0.98(0.74-1.29)$ & \\
\hline ECOG PS & & & & .090 & & .139 & & & & .009 & & .013 \\
\hline $0-1$ & 605 & $421(69.6)$ & 18.4 & & 1.00 (Ref) & & 605 & $404(66.8)$ & 6.6 & & 1.00 (Ref) & \\
\hline 2 & 554 & $42(77.8)$ & 17.7 & & $1.27(0.93-1.75)$ & & 54 & 43 (79.6) & 4.4 & & $1.49(1.09-2.05)$ & \\
\hline TNM stage & & & & .042 & & & & & & .419 & & \\
\hline$\| A$ & 49 & $29(59.2)$ & 27 & & 1.00 (Ref) & - & 49 & 37 (75.5) & 9 & & 1.00 (Ref) & - \\
\hline$\| \mathrm{IIB}$ & 189 & $136(71.9)$ & 18.4 & & $1.70(1.14-2.55)$ & .01 & 189 & $128(67.7)$ & 6 & & $1.13(0.78-1.64)$ & .510 \\
\hline IV & 422 & $300(71.1)$ & 17.7 & & $1.85(1.25-2.72)$ & .002 & 422 & $283(67.1)$ & 6.4 & & $1.18(0.83-1.68)$ & .358 \\
\hline Histologic type & & & & .017 & & & & & & .701 & & \\
\hline Adenocarcinoma & 429 & $286(66.7)$ & 19 & & 1.00 (Ref) & & 429 & $293(68.3)$ & 6.4 & & 1.00 (Ref) & - \\
\hline Squamous cell & 141 & $110(68.0)$ & 15 & & $1.32(1.03-1.67)$ & .026 & 141 & $92(65.2)$ & 6.9 & & $0.98(0.76-1.26)$ & .853 \\
\hline Adenosquamous carcinoma & 13 & $11(84.6)$ & 12.7 & & $1.80(0.98-3.32)$ & .059 & 13 & $8(61.5)$ & 6.6 & & $1.19(0.58-2.43)$ & .643 \\
\hline Other & 77 & $58(75.3)$ & 17.4 & & $1.27(0.95-1.70)$ & .102 & 77 & $54(70.1)$ & 6.2 & & $0.91(0.67-1.22)$ & .515 \\
\hline Gl toxicity & & & & .209 & & .267 & & & & .814 & & \\
\hline Absent & 586 & $406(69.3)$ & 18.6 & & 1.00 (Ref) & & 586 & $398(67.9)$ & 6.5 & & 1.00 (Ref) & - \\
\hline Present & 58 & $43(74.1)$ & 16.0 & & $1.20(0.87-1.67)$ & & 58 & $39(67.2)$ & 6.2 & & $0.98(0.69-1.38)$ & .933 \\
\hline Hematologic toxicity & & & & .837 & & .611 & & & & .414 & & .416 \\
\hline Absent & 481 & $133(69.2)$ & 18.0 & & 1.00 (Ref) & & 481 & $331(68.8)$ & 6.0 & & 1.00 (Ref) & \\
\hline Present & 166 & $122(73.5)$ & 17.8 & & $1.06(0.86-1.30)$ & & 166 & $107(64.5)$ & 6.9 & & $0.91(0.73-1.14)$ & \\
\hline Overall toxicity & & & & .831 & & .735 & & & & .456 & & .417 \\
\hline Absent & 436 & $299(68.6)$ & 18.6 & & 1.00 (Ref) & & 436 & $299(68.6)$ & 6.3 & & 1.00 (Ref) & \\
\hline Present & 200 & $145(72.5)$ & 18.4 & & $1.04(0.85-1.27)$ & & 200 & $132(66.0)$ & 6.9 & & $0.92(0.74-1.13)$ & \\
\hline
\end{tabular}


Supplemental Table 3 Stratification Analysis of MDM2 rs1470383 and Hematologic Toxicity by Clinical and Demographic Variables

\begin{tabular}{|c|c|c|c|c|}
\hline \multirow[b]{2}{*}{ Variable } & \multicolumn{2}{|c|}{ Toxicity Present/Absent (n) } & \multirow[b]{2}{*}{ OR $(95 \% \mathrm{Cl})^{\mathrm{a}}$} & \multirow[b]{2}{*}{$P$ Value $^{\mathrm{a}}$} \\
\hline & $\mathbf{A A}+\mathbf{A G}$ & GG & & \\
\hline \multicolumn{5}{|l|}{ Age (years) } \\
\hline$\leq 58$ & $68 / 254$ & $7 / 4$ & $6.56(1.84-23.43)$ & $.004^{\mathrm{b}}$ \\
\hline$>58$ & $84 / 233$ & $6 / 6$ & $2.53(0.77-8.27)$ & .124 \\
\hline \multicolumn{5}{|l|}{ Sex } \\
\hline Male & $103 / 346$ & $7 / 9$ & $2.67(0.96-7.49)$ & .072 \\
\hline Female & $94 / 136$ & $6 / 1$ & $15.22(1.74-133.35)$ & $.009^{b}$ \\
\hline \multicolumn{5}{|l|}{ Smoking status } \\
\hline Never smokers & $68 / 201$ & $6 / 1$ & $15.74(1.83-135.49)$ & $.003^{\mathrm{b}}$ \\
\hline Ever smokers & $84 / 186$ & $7 / 9$ & $2.73(0.95-7.77)$ & .061 \\
\hline \multicolumn{5}{|l|}{ Performance status } \\
\hline $0-1$ & $142 / 442$ & $13 / 9$ & $4.56(1.88-11.04)$ & $.0008^{b}$ \\
\hline 2 & $11 / 43$ & NA & NA & NA \\
\hline \multicolumn{5}{|l|}{ TNM stage } \\
\hline IIIA & $11 / 36$ & $2 / 0$ & NA & NA \\
\hline IIIB & $45 / 141$ & $1 / 2$ & $1.28(0.11-15.13)$ & .844 \\
\hline IV & $97 / 308$ & $10 / 8$ & $4.17(1.56-11.14)$ & $.004^{\mathrm{b}}$ \\
\hline \multicolumn{5}{|l|}{ Histologic type } \\
\hline Adenocarcinoma & $101 / 312$ & $10 / 7$ & $4.11(1.51-11.20)$ & $.001^{\mathrm{b}}$ \\
\hline Squamous cell & $31 / 108$ & $1 / 1$ & $1.41(0.08-24.18)$ & .812 \\
\hline Adenosquamous carcinoma & $3 / 9$ & $0 / 1$ & NA & NA \\
\hline Other & $18 / 56$ & $2 / 1$ & $10.87(0.59-200.89)$ & .198 \\
\hline
\end{tabular}

Abbreviations: $\mathrm{Cl}=$ confidence interval; $\mathrm{NA}=$ not applicable; $\mathrm{OR}=$ odds ratio.

aith adjustment for chemotherapy regimen.

${ }^{\mathrm{b}}$ Statistically significant.

\section{Supplemental Table 4 False-Positive Reporting Probability for SNPs Showing Significant Associations With Clinical Outcomes}

\begin{tabular}{|c|c|c|c|c|c|c|c|c|c|}
\hline \multirow[b]{2}{*}{ SNP } & \multirow[b]{2}{*}{ Clinical Outcomes } & \multirow{2}{*}{$\begin{array}{c}\text { Genetic } \\
\text { Model }\end{array}$} & \multirow{2}{*}{$\begin{array}{c}\text { HR/OR } \\
(95 \% \mathrm{Cl})\end{array}$} & \multirow[b]{2}{*}{$P$ Value } & \multirow{2}{*}{$\begin{array}{c}\text { Statistical } \\
\text { Power }\end{array}$} & \multicolumn{4}{|c|}{ Prior Probability $^{a}$} \\
\hline & & & & & & .25 & .1 & .01 & .001 \\
\hline \multirow[t]{5}{*}{ rs1470383 } & Overall toxicity ${ }^{\mathrm{b}}$ & Recessive & 3.37 (1.39-8.18) & .007 & 0.037 & $.079^{c}$ & .204 & .738 & .966 \\
\hline & Hematologic toxicity ${ }^{d}$ & Recessive & $4.08(1.73-9.58)$ & .001 & 0.15 & $.028^{\circ}$ & $.079^{\circ}$ & .486 & .905 \\
\hline & Overall survival $^{\mathrm{b}}$ & & & & & & & & \\
\hline & Absent overall toxicity & Additive & $1.39(1.11-1.75)$ & .004 & 0.74 & $.020^{c}$ & $.058^{\mathrm{C}}$ & .404 & .872 \\
\hline & Absent hematologic toxicity & Genotypic & $1.44(1.17-1.79)$ & .0008 & 0.64 & $.005^{\mathrm{c}}$ & $.014^{\mathrm{C}}$ & $.136^{c}$ & .613 \\
\hline rs1690924 & Gastrointestinal toxicity $^{e}$ & Genotypic & $2.32(1.30-4.14)$ & .004 & 0.60 & $.022^{c}$ & $.062^{\mathrm{C}}$ & .421 & .880 \\
\hline rs3730635 & $\begin{array}{l}\text { Overall survival for patients } \\
\text { without hematologic toxicity }\end{array}$ & Additive & $0.45(0.21-0.96)$ & .039 & 0.16 & .430 & .693 & .961 & .996 \\
\hline Haplotype AAG & Overall survival & Haplotype & $0.66(0.46-0.95)$ & .025 & 0.48 & $.137^{\circ}$ & .323 & .840 & .981 \\
\hline
\end{tabular}

Abbreviations: $\mathrm{Cl}=$ confidence interval; $\mathrm{HR}=$ hazard ratio; $\mathrm{OR}=$ odds ratio; SNP = single nucleotide polymorphism.

aprior effect sizes were assumed at 2.5 and 1.5 for SNPs for platinum toxicity and overall survival, respectively.

${ }^{\mathrm{b}}$ Adjusted for age, sex, TNM stage, and histologic type.

'Statistically significant.

${ }^{\mathrm{d}}$ Adjusted for chemotherapy regimen.

${ }^{\mathrm{e}}$ Adjusted for sex. 